\title{
The odor of origin: kinship and geographical distance are reflected in the marking pheromone of male beewolves (Philanthus triangulum F., Hymenoptera, Crabronidae)
} Martin Kaltenpoth ${ }^{\dagger 1,2}$, Johannes Kroiss* ${ }^{* 1,2}$ and Erhard Strohm ${ }^{1,2}$

\author{
Address: ${ }^{1}$ University of Würzburg, Department for Animal Ecology and Tropical Biology, Am Hubland, 97074 Würzburg, Germany and \\ ${ }^{2}$ University of Regensburg, Department for Zoology, 93040 Regensburg, Germany \\ Email: Martin Kaltenpoth - martin.kaltenpoth@biologie.uni-regensburg.de; Johannes Kroiss* - johannes.kroiss@biologie.uni-regensburg.de; \\ Erhard Strohm - erhard.strohm@biologie.uni-regensburg.de \\ * Corresponding author †Equal contributors
}

Published: 10 October 2007

BMC Ecology 2007, 7:II doi:10.1 I86/1472-6785-7-II
Received: 23 January 2007

Accepted: 10 October 2007

This article is available from: http://www.biomedcentral.com/I472-6785/7/II

(c) 2007 Kaltenpoth et al; licensee BioMed Central Ltd.

This is an Open Access article distributed under the terms of the Creative Commons Attribution License (http://creativecommons.org/licenses/by/2.0), which permits unrestricted use, distribution, and reproduction in any medium, provided the original work is properly cited.

\begin{abstract}
Background: Pheromones play an important role for mate finding and courtship in many insects. In species where males are the signaling sex, females are expected to choose among potential mates with regard to the emitter's quality and/or genetic compatibility. One important aspect is the balance between negative and positive effects of in- vs. outbreeding. In the present study, we aimed to assess the potential of the territory marking pheromone of European beewolves as an indicator for genetic compatibility in the context of female choice.
\end{abstract}

Results: We analyzed the sex pheromone composition of male European beewolves (Philanthus triangulum F., Hymenoptera, Crabronidae) from eight different locations across Central Europe (six in Germany, one in England, and one in Italy). The pheromone constitutes a complex blend of various long-chain hydrocarbons (alkanes, alkenes, alcohols, ketones, and a carbon acid). We demonstrate that pheromone composition differs significantly among distant populations (regional scale), among subpopulations (local scale) and between families within subpopulations. The differences in the pheromone blend are positively correlated with geographical distances as might be expected according to an isolation-by-distance model. On a local scale, family membership has a larger effect on pheromone composition than subpopulation affiliation, while the reverse is true for the regional scale.

Conclusion: Our results show that male pheromones can contain information on both kinship and geographical origin that may be used by females to choose adaptively among potential mates on the basis of their genetic distance.

\section{Background}

In many animals, sexual signals vary with the degree of kinship as well as with geographical distribution. This has been shown for numerous species with acoustical courtship signals [1-3], but also for several taxa with sex phe- romones [4-8]. Previous studies on chemical signals, however, have focused on pheromones produced by females; evidence for geographical variation in male sex pheromones is largely lacking [but see [9-12]]. 
Since there is usually a conflict of interest between the sexes [13], male sex pheromones are expected to underlie completely different selective pressures than female pheromones $[14,15]$. Male sexual signals often enable females to choose adaptively among potential mates by providing information on species affiliation and mate quality [16-19]. If males vary in their ability to provide essential resources to the females $[20,21]$ or in their parasite or disease load [22-24] and such differences in quality are indicated in the males' signals females could benefit directly by choosing a high-quality male. Females may also benefit indirectly, if offspring quality depends on the genetic background of the male. Several models have been proposed to explain female choice based on indirect benefits, the most prominent of these being the "good genes" model [25-27], and the model of the "best compatibility" $[20,28,29]$.

The genetic compatibility of a mate depends, among other things, on the degree of kinship which ranges from strict inbreeding to extensive outbreeding, both of which have certain advantages [30] and disadvantages [31,32]. According to the model of optimal outbreeding, females should choose a mate of a certain genetic distance to balance negative effects of inbreeding and outbreeding $[31,33,34]$.

Male European beewolves establish small territories in the vicinity of female nest aggregations, and territories do not contain any resources essential for beewolf females $[35,36]$. The males apply a marking pheromone from a cephalic gland (the postpharyngeal gland, PPG) onto plants within their territory and defend the territory against intruding males in combat flights without physical contact [35-40]. The marking pheromone of male European beewolves comprises a complex blend of up to 55 compounds $[38,40]$ that might contain important cues for females to assess male quality and/or compatibility.

Behavioral observations provide clear evidence that the marking pheromone of beewolf males attracts receptive females to the males' territories [37]. Females approach territories in a zigzagging flight pattern from the downwind side, probably orienting towards the windborne pheromone [37]. Copulations usually occur within the males' territories [35-37] and seem to be under the control of females since they can easily repel unwanted males by virtue of their larger body size [37] or refuse copulation by bending their abdomen tip downwards (E. Strohm, pers. observation). Territories of different males are often aggregated, thereby constituting a lek situation in which the females have an ideal opportunity to compare among potential mates and choose the most suitable $[35,37]$. Since the copulation is not preceded by any kind of visual display, female choice appears to be, at least predomi- nantly, based on information obtained from the male sex pheromone (E. Strohm, M. Kaltenpoth, J. Kroiss unpublished data). The amount and composition of the male PPG content have been shown to differ between families [41] and to vary with the age of the males [42].

Beewolves have good flying abilities and it is likely that individuals from different (sub)populations meet in the field. Thus, the discrimination between males belonging to different (sub)populations may be an important factor influencing female mate choice decisions. Using combined gas chromatography-mass spectrometry (GC-MS), we investigated whether the marking pheromone of male European beewolves varies between populations, between subpopulations, and among families within subpopulations in a way that might provide a basis for female choice. We compared the relative effects of population and family association on the composition of the pheromone and discuss the consequences for optimal mate choice.

\section{Results}

\section{Pheromone amount and composition}

Using coupled GC-MS, we found a total of 25 substances in the male sex pheromone: $(S)$-2,3-dihydrofarnesoic acid (DHFS hereafter); $(Z)$-9-octadecen-1-ol; $(Z)$-10-nonadecen-2-one; 1-octadecanol; heneicosane; "Unidentified substance 1" (unknown 1); "Unidentified substance 2"; docosane; $(Z)$-11-eicosen-1-ol; a mixture of (Z)-9-, (Z)-7tricosene, and $\Delta x$, y-tricosadiene; 1-eicosanol; tricosane; a mixture of (Z)-9-, (Z)-7-tetracosene, and $\Delta x$, y-tetracosadiene (C24en); tetracosane (C24an); a mixture of (Z)-9-, (Z)-7-pentacosene, and $\Delta \mathrm{x}$, y-pentacosadiene (C25en); pentacosane (C25an); a mixture of 7-, 11-, and 13-methyl pentacosane (m-C25an); (Z)-9-hexacosene (C26en); hexacosane (C26an); $\Delta$-16-pentacosen-8-one (C25one); a mixture of (Z)-9-, (Z)-7-heptacosene, and $\Delta x$, y-heptacosadiene (C27en); heptacosane (C27an); octacosane (C28an); nonacosane (C29an); hentriacontane (C31an). Several peaks had to be combined for the analysis, because they were not always clearly separated by the GCMS. This applies to $(Z)$-9-octadecen-1-ol and (Z)-10-nonadecen-2-one (C19enone hereafter), 1-octadecanol and heneicosane (C18anol), "Unidentified substance $2 "$ and docosane (C22ane), (Z)-11-eicosen-1-ol and tricosenes/ tricosadiene (C20enol), and 1-eicosanol and tricosane (C23ane). Thus, the 25 detected substances were reduced to 20 variables that were included in the analysis. This procedure is conservative with regard to the hypotheses tested.

The total amount of pheromone extracted from $P$. triangulum males varied between 101 and $2508 \mu \mathrm{g}$ (mean \pm SD = $655 \pm 377 \mu \mathrm{g}$ ). In both data sets, the sampled populations differed significantly in their total amount of pheromone 
(data set 1: ANOVA, $\mathrm{F}_{5,254}=6.66, \mathrm{p}<0.01$; data set 2: ANOVA, $\left.\mathrm{F}_{4,128}=3.99, \mathrm{p}<0.01\right)$.

\section{Chemical dimorphism}

The pheromone composition showed a distinct dimorphism [see [40] for a detailed description of the dimorphism]. The two morphs differ mainly in the relative proportions of pentacosene (mixture of isomers with $(Z)$ 9-pentacosene as the main component) and heptacosene (mixture of isomers with (Z)-9-heptacosene as the main component), and they can be distinguished unambiguously by the relative amount of heptacosene, which shows a clearly bimodal distribution [40]. The morph with the high proportion of pentacosene (in the following called $\mathrm{C}_{25}$-type) was overall the more common type (79.1\% of all males) compared to the one having approximately equal proportions of penta- and heptacosene $\left(\mathrm{C}_{25} / \mathrm{C}_{27^{-}}\right.$ type in the following; $20.9 \%$ of all males) [see also [40]]. The frequency of the $\mathrm{C}_{25}$-type varied considerably between the sampled populations from 8.3 to $100.0 \%$ in the sampled populations (mean $\pm \mathrm{SD}=72.6 \pm 26.3 \%$ ). Since chance variations in the proportion of $\mathrm{C}_{25}-$ and $\mathrm{C}_{25} /$ $\mathrm{C}_{27}$-type males among families and among populations can greatly influence the outcome of statistical analyses on the chemical differentiation, all of the following analyses were performed on $\mathrm{C}_{25}$ - and $\mathrm{C}_{25} / \mathrm{C}_{27}$-type individuals combined as well as on $\mathrm{C}_{25}$-type individuals only.

\section{Population differentiation}

The analysis of geographical variation in the male beewolf sex pheromone was conducted with two data sets on two geographical scales. The first data set (data set 1) was focused on a local scale (subpopulation level), the second data set (data set 2) with emphasis on a regional scale (population level). Populations in both data sets and, thus, on two different spatial scales could be significantly separated by discriminant analyses (DAs) (Table 1, Fig. 1 and 2). This was irrespective of the inclusion or omission of the $\mathrm{C}_{25} / \mathrm{C}_{27}$-type in the analysis. Classification of DA revealed that 45.0 to $56.1 \%$ of males were correctly assigned to the populations, depending on the data set and inclusion or omission of the $\mathrm{C}_{25} / \mathrm{C}_{27}$-type (20.0 or $25.0 \%$ correct classifications would have been expected by chance). Despite the higher number of groups in the DA, the classification results were generally more accurate for the samples on the regional than on the local scale, indicating that the chemical distances were positively correlated with the geographical scale.

\section{Family differentiation}

Families within populations could be significantly separated in six out of eight populations by DAs (Table 1, Fig. 3 ). Individual males were correctly classified in 58.1 to $100.0 \%$ of cases ( 14.3 to $50.0 \%$ correct classifications would have been expected by chance). Although DAs were not always significant, the overall classifications of families within populations were more accurate than classifications between populations even if different numbers of groups in the DA are taken into account. Thus, males belonging to different populations and males belonging to different families within a population can be separated from each other on the basis of quantitative differences in some of the pheromone compounds.

\section{Relative effects of family and population affiliation on pheromone composition}

To assess the relative effects of family and population affiliation on the pheromone composition of male European beewolves, we conducted a multivariate nested ANOVA on the Aitchison-transformed relative peak areas with

Table I: Population and family differentiation by principal components and discriminant analyses

\begin{tabular}{|c|c|c|c|c|c|c|c|c|c|c|c|c|c|}
\hline Scale & (Sub)Population(s) & Data set & Families & Type & $\mathbf{n}$ & $\begin{array}{l}\text { PCA } \\
\text { Fact. }\end{array}$ & Expl.Var.(\%) & $\begin{array}{c}\text { Discriminant } \\
\text { analysis } \\
\text { Funct. }\end{array}$ & Wilk's- $\lambda$ & $\chi^{2}$ & df & $\mathbf{p}$ & Corr.class.(\%) \\
\hline Regional & W.S. D. I. E & 2 & - & both & 133 & 7 & 84.07 & 4 & 0.531 & 79.65 & 28 & 0.000 & 52.6 \\
\hline Regional & W.S. D. I. E & 2 & - & $\mathrm{C}_{25}$ & 107 & 7 & 83.79 & 4 & 0.485 & 72.40 & 28 & 0.000 & 56.1 \\
\hline Local & $W_{B} \cdot W_{C} \cdot V \cdot R$ & 1 & - & both & 191 & 6 & 80.58 & 3 & 0.604 & 93.30 & 18 & 0.000 & 45.0 \\
\hline Local & $W_{B} \cdot W_{C} \cdot V \cdot R$ & 1 & - & $\mathrm{C}_{25}$ & 175 & 6 & 80.41 & 3 & 0.611 & 83.14 & 18 & 0.000 & 49.7 \\
\hline Family & $W_{B}$ & 1 & 4 & both & 45 & 7 & 84.87 & 3 & 0.292 & 47.43 & 21 & 0.001 & 60.0 \\
\hline Family & $W_{B}$ & 1 & 4 & $\mathrm{C}_{25}$ & 44 & 7 & 86.09 & 3 & 0.240 & 53.44 & 21 & 0.000 & 75.0 \\
\hline Family & $w_{c}$ & 1 & 7 & $\mathrm{C}_{25}$ & 74 & 5 & 79.76 & 5 & 0.097 & 156.25 & 30 & 0.000 & 58.1 \\
\hline Family & W & 2 & 4 & $\mathrm{C}_{25}$ & 36 & 6 & 84.62 & 3 & 0.206 & 47.44 & 18 & 0.000 & 66.7 \\
\hline Family & V & 1 & 3 & both & 28 & 4 & 81.03 & 2 & 0.557 & 13.73 & 8 & 0.089 & 60.7 \\
\hline Family & $\mathrm{V}$ & I & 3 & $\mathrm{C}_{25}$ & 24 & 4 & 77.46 & 2 & 0.614 & 9.51 & 8 & 0.301 & 62.5 \\
\hline Family & $S$ & I & 3 & both & 28 & 4 & 81.07 & 2 & 0.116 & 50.62 & 8 & 0.000 & 89.3 \\
\hline Family & $S$ & 2 & 3 & both & 20 & 3 & 66.36 & 2 & 0.358 & 16.45 & 6 & 0.012 & 60.0 \\
\hline
\end{tabular}

"Type" indicates, whether only the $C_{25}$-type or both $C_{25^{-}}$and $C_{25} / C_{27}$-type were included in the analysis. For PCAs, the number of factors as well as the cumulative explained variance is given. For DAs, the number of functions, Wilk's- $\lambda$, $\chi^{2}$, degrees of freedom, $p$-value, and the percentage of correct classifications by DA are given. (Population abbreviations: W: Würzburg, Germany; $W_{\mathrm{B}}$ : Würzburg, Biocenter, Germany; $W_{\mathrm{C}}$ : Würzburg, City, Germany; V: Veitshöchheim, Germany; R: Retzbach, Germany; D: Düsseldorf, Germany; I: Vizzola Ticino, Italy; E: Puttenham, UK). 


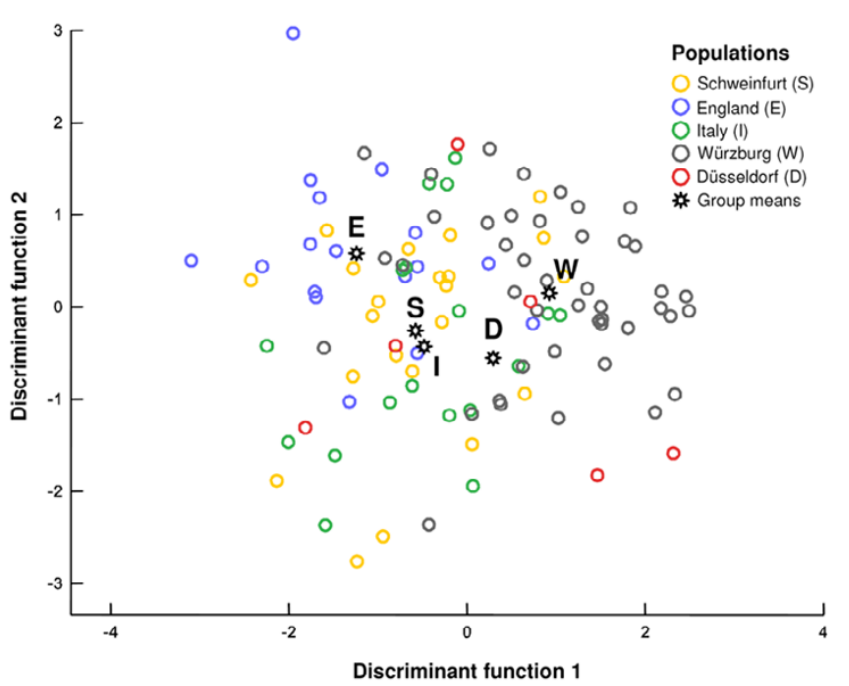

Figure I

Discriminant analysis of geographical variation of the sex-pheromone on the regional scale. Despite some overlap, the populations are significantly separated (data set 2 , five populations, $\mathrm{C}_{25}$-type only; see Table I and text for details).

family membership as a nested factor within populations. Both family and population affiliation had significant effects on the pheromone composition in each dataset, regardless of the omission or inclusion of $\mathrm{C}_{25} / \mathrm{C}_{27}$-type males in the analysis (Table 2). Together, family and pop-

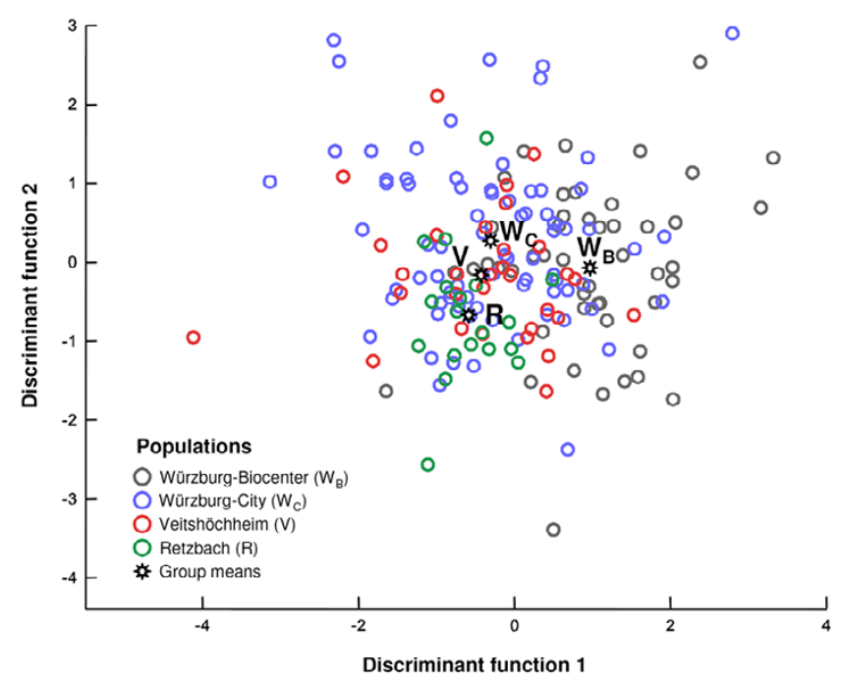

Figure 2

Discriminant analysis of geographical variation of the sex-pheromone on the local scale. Despite broad overlap, the populations are significantly separated (data set I, four subpopulations, $\mathrm{C}_{25}$-type only; see Table I and text for details).

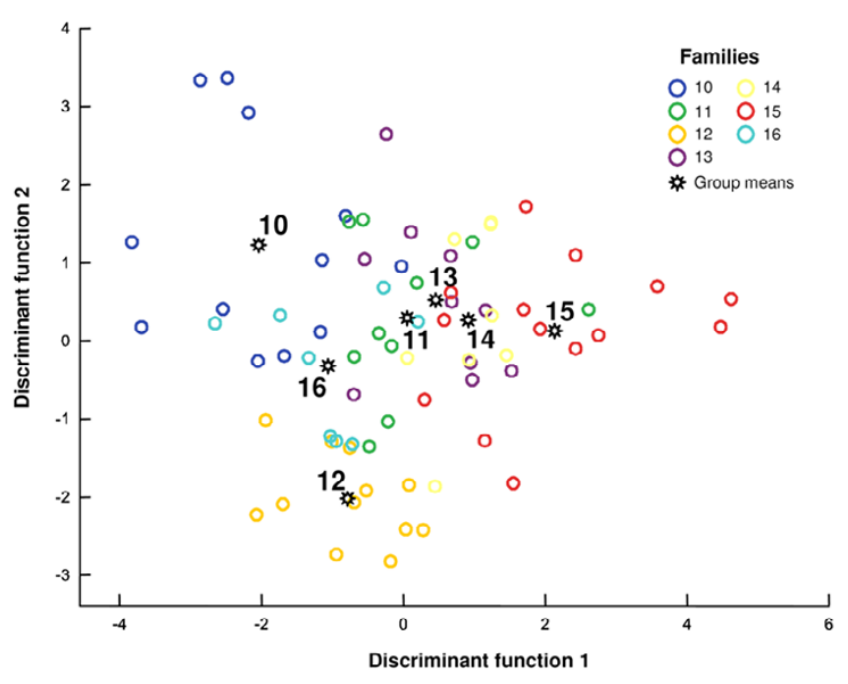

Figure 3

Discriminant analysis of the variation of the sex-pheromone on the family level. Despite some overlap, the families are significantly separated (data set I, one population: Würzburg City, $C_{25}$-type only; see Table I and text for details).

ulation affiliation explained between 11.4 and $90.8 \%$ of the variance in peak areas. The distribution of $\eta^{2}$-values did not deviate significantly from a normal distribution for any of the analyses (Kolmogorov-Smirnov tests: $\mathrm{Z} \leq$ $1.16, \mathrm{p} \geq 0.135$ for all tests).

On a local scale (data set 1), family membership explained a significantly higher proportion of the variance in pheromone composition than subpopulation affiliation (paired t-tests, $\mathrm{C}_{25^{-}}$and $\mathrm{C}_{25} / \mathrm{C}_{27}$-type: $\mathrm{t}_{19}=-6.22, \mathrm{p}<$ $0.001 ; \mathrm{C}_{25}$-type only: $\left.\mathrm{t}_{19}=-6.17, \mathrm{p}<0.001\right)$. On a regional scale (data set 2), however, this effect was reversed, with population affiliation explaining more of the variance, although this effect was only significant when both $\mathrm{C}_{25^{-}}$ and $\mathrm{C}_{25} / \mathrm{C}_{27}$-type males were included (paired t-tests, $\mathrm{C}_{25^{-}}$ and $\mathrm{C}_{25} / \mathrm{C}_{27}$-type: $\mathrm{t}_{19}=2.11, \mathrm{p}=0.048 ; \mathrm{C}_{25}$-type only: $\mathrm{t}_{19}$ $=1.84, \mathrm{p}=0.081)$.

\section{Correlation between geographical and chemical distance}

To test for a correlation between the matrices of geographical and chemical distances of the populations we performed a Mantel test. We detected a strong correlation between geographical and chemical distance for data set 1 and the normalized combination of both datasets irrespective of which combination of populations was used as a reference for normalization and independent of the inclusion or omission of the $\mathrm{C}_{25} / \mathrm{C}_{27}$-type in the analysis (Tables 3 and 4, Fig. 4). A Mantel test restricted to data set 2 revealed no significant correlation. 
Table 2: Relative effects of family and (sub)population affiliation on pheromone composition in male European beewolves

\begin{tabular}{|c|c|c|c|c|c|c|c|c|}
\hline \multirow[b]{2}{*}{ Peak } & \multicolumn{2}{|c|}{ Data set I: Local $C_{25^{-}}$and $C_{25} / C_{27}$-type } & \multicolumn{2}{|c|}{ Data set I: Local $C_{25}$-type only } & \multicolumn{2}{|c|}{ Data set 2: Regional $C_{25^{-}}$and $C_{25} / C_{27^{-t y p e}}$} & \multicolumn{2}{|c|}{ Data set 2: Regional $C_{25}$-type only } \\
\hline & $\eta^{2}$ (Pop) & $\eta^{2}$ (Fam) & $\eta^{2}$ (Pop) & $\eta^{2}($ Fam) & $\eta^{2}$ (Pop) & $\eta^{2}$ (Fam) & $\eta^{2}$ (Pop) & $\eta^{2}$ (Fam) \\
\hline DHFS & 0.024 & 0.110 & 0.010 & 0.109 & 0.041 & 0.118 & 0.084 & 0.101 \\
\hline Cl9enone & 0.089 & 0.243 & 0.086 & 0.250 & 0.439 & 0.060 & 0.462 & 0.105 \\
\hline Cl8anol & 0.118 & 0.166 & 0.133 & 0.168 & 0.268 & 0.162 & 0.188 & 0.191 \\
\hline unknown I & 0.055 & 0.074 & 0.033 & 0.081 & 0.273 & 0.070 & 0.207 & 0.076 \\
\hline C22ane & 0.024 & 0.302 & 0.025 & 0.337 & 0.053 & 0.200 & 0.040 & 0.263 \\
\hline C20enol & 0.088 & 0.063 & 0.083 & 0.072 & 0.137 & 0.085 & 0.152 & 0.079 \\
\hline C23ane & 0.036 & 0.079 & 0.056 & 0.083 & 0.336 & 0.190 & 0.308 & 0.244 \\
\hline C24ene & 0.044 & 0.354 & 0.012 & 0.376 & 0.069 & 0.185 & 0.162 & 0.139 \\
\hline C24ane & 0.085 & 0.200 & 0.060 & 0.200 & 0.116 & 0.033 & 0.083 & 0.036 \\
\hline C25ene & 0.001 & 0.190 & 0.016 & 0.217 & 0.062 & 0.156 & 0.126 & 0.154 \\
\hline C25ane & 0.062 & 0.165 & 0.026 & 0.136 & 0.161 & 0.071 & 0.081 & 0.079 \\
\hline $\mathrm{mC} 25 \mathrm{ene}$ & 0.152 & 0.327 & 0.119 & 0.330 & 0.174 & 0.094 & 0.232 & 0.098 \\
\hline C26ene & 0.001 & 0.182 & 0.107 & 0.301 & 0.284 & 0.072 & 0.307 & 0.096 \\
\hline C26ane & 0.225 & 0.247 & 0.209 & 0.230 & 0.146 & 0.056 & 0.093 & 0.045 \\
\hline C25enone & 0.012 & 0.239 & 0.012 & 0.243 & 0.222 & 0.289 & 0.397 & 0.511 \\
\hline C27ene & 0.014 & 0.188 & 0.105 & 0.276 & 0.255 & 0.074 & 0.178 & 0.037 \\
\hline C27ane & 0.205 & 0.388 & 0.191 & 0.397 & 0.133 & 0.141 & 0.091 & 0.083 \\
\hline C28ane & 0.074 & 0.141 & 0.066 & 0.119 & 0.046 & 0.085 & 0.051 & 0.080 \\
\hline C29ane & 0.080 & 0.166 & 0.045 & 0.165 & 0.219 & 0.140 & 0.168 & 0.080 \\
\hline C3lane & 0.076 & 0.135 & 0.068 & 0.135 & 0.270 & 0.197 & 0.285 & 0.216 \\
\hline \multicolumn{9}{|c|}{ MANOVA results: } \\
\hline Pillai's trace & 0.944 & 3.582 & 0.988 & 3.703 & 2.029 & 2.414 & 2.301 & 2.618 \\
\hline $\mathbf{F}$ & 5.137 & 2.994 & 5.366 & 3.019 & 3.501 & 1.869 & 3.184 & 1.897 \\
\hline $\mathbf{p}$ & 0.000 & 0.000 & 0.000 & 0.000 & 0.000 & 0.000 & 0.000 & 0.000 \\
\hline
\end{tabular}

Proportions of variance explained by family and population membership in nested MANOVAs are estimated for each peak by partial $\eta^{2}$-values. MANOVA results are given for each data set, including and excluding $\mathrm{C}_{25} / \mathrm{C}_{27}$-type males, respectively (see text for peak abbreviations). 
Table 3: Correlation between geographic and chemical distances of populations of $P$. triangulum

\begin{tabular}{|c|c|c|c|c|c|c|}
\hline \multirow[b]{2}{*}{ Data set } & \multirow[b]{2}{*}{ Scale } & \multirow[b]{2}{*}{ Populations } & \multirow[b]{2}{*}{ Type } & \multirow[b]{2}{*}{ Normalization } & \multicolumn{2}{|c|}{ Mantel test } \\
\hline & & & & & $\mathbf{r}^{2}$ & $\mathbf{p}$ \\
\hline I & Local & $W_{B}, W_{C}, V, R, S, D$ & both & - & 0.854 & 0.003 \\
\hline 1 & Local & $W_{B}, W_{C}, V, R, S, D$ & $\mathrm{C}_{25}$ & - & 0.584 & 0.004 \\
\hline 2 & Regional & W, S, D, I, E & both & - & 0.092 & 0.254 \\
\hline 2 & Regional & W, S, D, I, E & $\mathrm{C}_{25}$ & - & 0.074 & 0.319 \\
\hline 1 and 2 & Local+Regional & $\mathrm{W}, \mathrm{W}_{\mathrm{B}}, \mathrm{W}_{\mathrm{C}}, \mathrm{V}, \mathrm{R}, \mathrm{S}, \mathrm{D}, \mathrm{I}, \mathrm{E}$ & both & S-W & 0.468 & 0.008 \\
\hline 1 and 2 & Local+Regional & $W, W_{B}, W_{C}, V, R, S, D, I, E$ & both & $\mathrm{D}-\mathrm{W}$ & 0.608 & 0.003 \\
\hline 1 and 2 & Local+Regional & $\mathrm{W}, \mathrm{W}_{\mathrm{B}}, \mathrm{W}_{\mathrm{C}}, \mathrm{V}, \mathrm{R}, \mathrm{S}, \mathrm{D}, \mathrm{I}, \mathrm{E}$ & both & S-D & 0.581 & 0.004 \\
\hline 1 and 2 & Local+Regional & $\mathrm{W}, \mathrm{W}_{\mathrm{B}}, \mathrm{W}_{\mathrm{C}}, \mathrm{V}, \mathrm{R}, \mathrm{S}, \mathrm{D}, \mathrm{I}, \mathrm{E}$ & $\mathrm{C}_{25}$ & $S-W$ & 0.253 & 0.016 \\
\hline 1 and 2 & Local+Regional & $\mathrm{W}, \mathrm{W}_{\mathrm{B}}, \mathrm{W}_{\mathrm{C}}, \mathrm{V}, \mathrm{R}, \mathrm{S}, \mathrm{D}, \mathrm{I}, \mathrm{E}$ & $\mathrm{C}_{25}$ & $D-W$ & 0.397 & 0.013 \\
\hline 1 and 2 & Local+Regional & $\mathrm{W}, \mathrm{W}_{\mathrm{B}}, \mathrm{W}_{\mathrm{C}}, \mathrm{V}, \mathrm{R}, \mathrm{S}, \mathrm{D}, \mathrm{I}, \mathrm{E}$ & $\mathrm{C}_{25}$ & S-D & 0.362 & 0.005 \\
\hline
\end{tabular}

Given are coefficients of determination $\left(r^{2}\right)$ and p-values of Mantel tests. The column "type" indicates, whether only the $C_{25}$-type or both $C_{25}$ and $\mathrm{C}_{25} / \mathrm{C}_{27}$-type were included in the analysis. Data sets I and 2 were normalized to Würzburg - Schweinfurt (W-S), Würzburg - Düsseldorf (W-D), or Schweinfurt - Düsseldorf (S-D). For population abbreviations see Table I. P-values $<0.05$ are given in bold.

\section{Discussion}

In the present study, we investigated inter-individual differences in the pheromone composition of male European beewolves on three different levels: between families, among subpopulations on a local scale, and among geographically distant populations on a regional scale. Our results show that there are significant differences in pheromone composition on all three levels and that the chemical distance between populations is correlated with the geographical distance.

Although local subpopulations as well as geographically distant populations of beewolves could be separated on the basis of the male sex pheromone, only $45-56 \%$ of the individual males were classified correctly by the discriminant analyses, and chemical profiles of different populations overlapped considerably. However, the existing differences might be sufficient for females to reduce the

Table 4: Geographical and chemical distances between the nine sampled (sub)populations of $P$. triangulum

\begin{tabular}{cccccccccc}
\hline & $\mathbf{W}$ & $\mathbf{W}_{\mathbf{B}}$ & $\mathbf{W}_{\mathbf{C}}$ & $\mathbf{V}$ & $\mathbf{R}$ & $\mathbf{S}$ & $\mathbf{D}$ & $\mathbf{I}$ & $\mathbf{E}$ \\
\hline $\mathbf{W}$ & - & $N A$ & 4 & 6 & 18 & 31 & 274 & 472 & 746 \\
$\mathbf{W}_{\mathbf{B}}$ & $N A$ & - & 4 & 6 & 18 & 31 & 274 & 472 & 746 \\
$\mathbf{W}_{\mathbf{C}}$ & $N A$ & 0.29 & - & 3 & 15 & 32 & 270 & 473 & 743 \\
$\mathbf{V}$ & $N A$ & 0.58 & 0.47 & - & 13 & 33 & 267 & 474 & 740 \\
$\mathbf{R}$ & $N A$ & 0.70 & 0.55 & 0.68 & - & 31 & 256 & 485 & 732 \\
$\mathbf{S}$ & $I .73$ & 0.76 & 0.82 & 0.57 & 1.13 & - & 276 & 501 & 758 \\
$\mathbf{D}$ & $I .00$ & $I .00$ & 0.97 & 0.81 & 0.79 & 1.08 & - & 635 & 479 \\
$\mathbf{I}$ & $I .59$ & $N A$ & $N A$ & $N A$ & $N A$ & 0.64 & $1.5 I$ & - & 911 \\
$\mathbf{E}$ & 3.48 & $N A$ & $N A$ & $N A$ & $N A$ & 2.23 & 3.40 & 2.41 & - \\
\end{tabular}

Chemical distances (normalized to Würzburg - Düsseldorf) are displayed in italics in the lower left half of the table, geographical distances in the upper right half of the table. For population abbreviations see Table I. incidence of outbreeding, especially because the sensitivity of female chemoreceptors and the discriminatory ability of their central nervous system may exceed that of our analytical methods by several orders of magnitude $[43,44]$. Furthermore, our data provide only a lower boundary for the actual effect of geographical origin on the pheromone composition, since all the animals were reared under identical conditions in the laboratory. In the field, developmental conditions certainly vary between (sub)populations. Differences in environmental factors during larval development have been shown to affect the pheromone composition of male beewolves (K. Roeser-

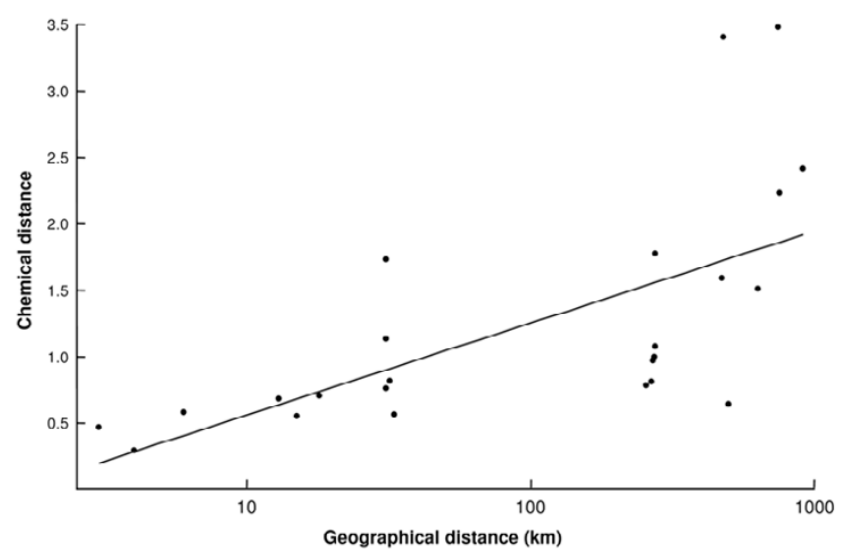

Figure 4

Correlation between pairwise geographic and chemical distances of populations of $\boldsymbol{P}$. triangulum males.

The trend line was obtained by linear regression in order to visualize the association (data sets $\mathrm{I}$ and $2 ; \mathrm{C}_{25}$-type only; normalization: Würzburg - Düsseldorf; Mantel-test: $r=$ 0.630, $p=0.013$; see also Table 4 and text for details). 
Mueller, M. Kaltenpoth \& E. Strohm, unpubl. data). Therefore, actual differences between populations in the field may be much larger than those observed under controlled conditions in the laboratory and might allow females a better discrimination of males from different (sub)populations.

Since beewolves have good flying abilities and are pioneer species that frequently colonize new habitats [45], females are likely to encounter males from other local subpopulations in the field (whereas it is unlikely that they encounter individuals from distant populations). Thus, female beewolves may use the information contained in the male pheromone to avoid outbreeding depression. Deleterious effects of extensive outbreeding have been demonstrated in many recent studies [46-48], and several hypotheses have been proposed to explain why outbreeding depression occurs [e.g. break-up of coadapted gene complexes, disruption of epistatic interactions, loss of local adaptations, dispersal hazards, and risk of parasite infection; see [31,32]].

Within populations, beewolf male pheromones differ significantly among families [this study and [41]]. The family-related differences may enable females to reduce the chances of mating with close kin and thereby avoid inbreeding depression, which is likely to impose especially high costs on beewolves. Kin recognition in animals is generally mediated by one of three mechanisms: phenotype matching, recognition of genetically compatible mates, or imprinting or learning of the individuals that occur in the same nest or birth place $[32,49,50]$. The mechanisms by which female beewolves could distinguish between kin and non-kin are unclear [for discussion see [41]]. The discrimination of males from different populations may be possible for females by sampling pheromones from different males in a lek and avoiding individuals with a pheromone blend that differs markedly from the population mean. Further studies are necessary to elucidate the mechanisms of kin- and population-recognition in European beewolves.

The multivariate nested ANOVAs indicate that pheromone composition is affected more strongly by family than subpopulation affiliation on a local scale, whereas the effect of population affiliation on a regional level is larger than the family effect (Table 2 ). These results are consistent with the positive correlation between chemical and geographical distance (Fig. 4) and suggest that (1) the subpopulations sampled on the local scale may be connected by a relatively frequent interchange of individuals and might, thus, represent a single population, and (2) small differences in the chemical profile between local subpopulations may add up on a regional scale according to an isolation-by-distance model [51]. Interestingly, the family effect exceeds the local subpopulation effect, making family differentiation potentially easier for beewolf females than subpopulation discrimination.

Generally, conspecific populations differ genetically only if the gene flow is sufficiently counterbalanced by the divergent forces of genetic drift or natural selection [52]. The reasons for the geographical differentiation in pheromone composition of male European beewolves are not yet known. However, selection pressures might vary among populations and may account for the observed differences. Males in colder regions, for example, may be selected for a greater abundance of pheromone substances with high volatility compared to males from warmer regions. Alternatively, female preferences for pheromone characteristics may vary among populations and cause a divergence of the pheromone composition at different localities.

\section{Conclusion}

Using GC-MS, we were able to detect differences in the sex pheromone composition of male European beewolves between families as well as among (sub)populations on both a regional and a local scale, with pheromone differentiation being significantly correlated with geographical distance. If female beewolves use this information on kinship and geographical origin contained in the male sex pheromone, they may be able to choose adaptively among potential mates according to the model of optimal outbreeding, thus, avoiding the deleterious effects of both in- and outbreeding by choosing a mate of intermediate genetic distance $[31,53]$. Studies considering both in- and outbreeding avoidance in an integrated model of "optimal outbreeding" are scarce [but see [54-56]]. The European beewolf constitutes an interesting model system to test for optimal outbreeding in a species with a complex male sex pheromone, and further studies may show whether females indeed use the male pheromone to avoid in- and outbreeding.

\section{Methods \\ Insects and sampling}

In 2004, four subpopulations with distances ranging from 3 to $18 \mathrm{~km}$ (median $=10 \mathrm{~km}$ ) were sampled $($ data set 1 : local scale; subpopulations: Würzburg, Biocenter, Germany, (49 $46^{\prime} 47^{\prime \prime} \mathrm{N}$, 09 58'11'E), Würzburg, City, Germany, (49 $\left.47^{\prime} 56^{\prime \prime} \mathrm{N}, \quad 09^{\circ} 55^{\prime} 38^{\prime \prime} \mathrm{E}\right), \quad$ Veitshöchheim, Germany, (49 48'20'N, 09 53'22'"E), Retzbach, Germany, (49 $\left.54^{\prime} 55^{\prime \prime} \mathrm{N}, 09^{\circ} 49^{\prime} 16^{\prime \prime} \mathrm{E}\right)$ ). Additionally, specimens from two distant populations in Germany were sampled to allow the combination with data set 2 for the analysis of the association between chemical and geographical distance (Schweinfurt, Germany, (50 03'00'N, $\left.10^{\circ} 14^{\prime} 00^{\prime \prime} \mathrm{E}\right)$, and Düsseldorf, Germany, (51 $11^{\circ} 13^{\prime \prime} \mathrm{N}$, $\left.6^{\circ} 48^{\prime} 09^{\prime \prime} \mathrm{E}\right)$ ). The distant populations were not included 
in the analysis of the chemical differentiation between the subpopulations. In 2005, we were able to sample five populations with distances ranging from 31 to $911 \mathrm{~km}$ $($ median $=490 \mathrm{~km})($ data set 2 : regional scale; populations: Würzburg, Germany, (49 $46^{\prime} 47^{\prime \prime N}$, 09 $\left.58^{\circ} 11^{\prime \prime E}\right)$, Schweinfurt, Germany, $\left(50^{\circ} 03^{\prime} 00^{\prime \prime} \mathrm{N}, 10^{\circ} 14^{\prime} 00^{\prime \prime} \mathrm{E}\right)$, Düsseldorf, Germany, $\left(51^{\circ} 11^{\prime} 13^{\prime \prime N}, 6^{\circ} 48^{\prime} 09^{\prime \prime E}\right)$, Vizzola Ticino near Milano, Italy, $\left(45^{\circ} 37^{\prime} 35^{\prime \prime} \mathrm{N}, 08^{\circ} 42^{\prime} 14^{\prime \prime} \mathrm{E}\right)$, and Puttenham near London, UK, $\left(51^{\circ} 13^{\prime} 20^{\prime \prime} \mathrm{N}\right.$, $\left.0^{\circ} 40^{\prime} 02^{\prime \prime} \mathrm{W}\right)$ ).

Female European beewolves were collected at each of the locations given above. They were transferred to laboratory cages at the University of Würzburg and reared after Strohm [36]. Cocoons with larvae of the F1 generation were placed individually in Eppendorf tubes and kept in boxes with moist sand at $10^{\circ} \mathrm{C}$ for four to nine months of overwintering. Cocoons were then transferred to warm conditions (cycles of 12 hours at $25^{\circ} \mathrm{C}$ and 12 hours at $22^{\circ} \mathrm{C}$ ) and adult beewolves emerged four to six weeks later. Emerging males were marked individually with up to three spots of acrylic paint on the dorsal side of the thorax and were allowed to fly in a climate chamber $(2.5 \times 1.8$ $\times 2.1 \mathrm{~m}$ in size) with $12 \mathrm{~h}$ light/dark cycles at $25^{\circ} \mathrm{C} / 20^{\circ} \mathrm{C}$ and provided with honey ad libitum. Since very young males have been shown to considerably differ in amount and composition of the pheromone [42] males were all caught at an age of 12-17 days and kept in small polystyrol vials (height: $80 \mathrm{~mm}$; diameter: $35 \mathrm{~mm}$ ) with moist sand and a drop of honey for two days to allow the pheromone glands to be replenished. After anesthetizing the males with $\mathrm{CO}_{2}$, they were killed by freezing and kept frozen $\left(\right.$ at $\left.-20^{\circ} \mathrm{C}\right)$ until extraction of the pheromone and GCMS analysis.

Overall, 393 males were used for the analysis (Data set 1: Würzburg, Biocenter, Germany: 54, Würzburg, City, Germany: 76, Veitshöchheim, Germany: 35, Retzbach, Germany: 26, Schweinfurt, Germany: 57, and Düsseldorf, Germany: 12; Data set 2: Würzburg, Germany: 46, Schweinfurt, Germany: 26, Düsseldorf, Germany: 8, Vizzola Ticino, Italy: 24, and Puttenham, UK: 29).

\section{Gas chromatography - mass spectrometry}

Frozen males were decapitated and their heads were cut at both sides to open up the postpharyngeal gland, which is the storage organ of the male sex pheromone $[40,57]$. Heads were placed individually in glass vials $(1.5 \mathrm{ml})$, and $20 \mu \mathrm{l}$ of a $1 \mathrm{~g} / \mathrm{l}$ solution of octadecane in hexane (equivalent to a final amount of $20 \mu \mathrm{g}$ of octadecane) was added as an internal standard to each vial to allow quantification of the pheromone. The heads were then submerged in approximately $1 \mathrm{ml}$ distilled hexane and chemicals were extracted for four hours.
After extraction, samples were analyzed immediately by coupled capillary gas chromatography-mass spectrometry (GC-MS) with an Agilent 6890N Series gas chromatograph (Agilent Technologies, Böblingen, Germany) coupled to an Agilent 5973 inert mass selective detector. The two data sets were run on the same GC-MS device, but with different capillary columns and slightly different temperature programs. GC-MS set-up 1 (data set 1): The GC was equipped with a HP-5 fused silica capillary column (J\&W, $30 \mathrm{~m} \times 0.32 \mathrm{~mm}$ ID; $\mathrm{df}=0.25 \mu \mathrm{m}$; temperature program: from $60^{\circ} \mathrm{C}$ to $300^{\circ} \mathrm{C}$ at $5^{\circ} \mathrm{C} / \mathrm{min}$, held constant for $1 \mathrm{~min}$ at $60^{\circ} \mathrm{C}$ and for $10 \mathrm{~min}$ at $300^{\circ} \mathrm{C}$ ). GCMS set-up 2 (data set 2): The GC was equipped with a RH$5 \mathrm{~ms}+$ fused silica capillary column $(\mathrm{J} \& \mathrm{~W}, 30 \mathrm{~m} \times 0.25 \mathrm{~mm}$ $\mathrm{ID} ; \mathrm{df}=0.25 \mu \mathrm{m}$; temperature program: from $120^{\circ} \mathrm{C}$ to $300^{\circ} \mathrm{C}$ at $3^{\circ} \mathrm{C} / \mathrm{min}$, held constant for $1 \mathrm{~min}$ at $120^{\circ} \mathrm{C}$ and for $1 \mathrm{~min}$ at $300^{\circ} \mathrm{C}$ ).

Helium was used as the carrier gas with a constant flow of $1 \mathrm{ml} / \mathrm{min}$. A split/splitless injector was used $\left(250^{\circ} \mathrm{C}\right)$ with the purge valve opened after $60 \mathrm{sec}$. The electron impact mass spectra (EI-MS) were recorded with an ionization voltage of $70 \mathrm{eV}$, a source temperature of $230^{\circ} \mathrm{C}$ and an interface temperature of $315^{\circ} \mathrm{C}$. Since preliminary analyses had revealed that the total amount of chemicals in the sample has an effect on the detection and quantification of certain components, samples in which the pheromone concentration was either too high or too low were rerun after adjusting the pheromone concentration by addition or evaporation of hexane.

\section{Statistical analysis}

Pheromone amount and composition

In the pheromone extracts, 25 components could be reliably detected in all samples, and their peaks were manually integrated with MSD ChemStation software (Agilent Technologies). The substances were identified by comparison of mass spectra and retention times with earlier analyses $[38,40]$. Not all substances described as components of the pheromone by Kroiss et al. [40] could be detected due to the low concentrations of the pheromone extracted from single males. Using the octadecane peak as an internal standard, the total amount of pheromone was calculated and then $\log _{10}$-transformed to obtain normally distributed data for statistical analysis. The $\log _{10}$-transformed absolute amounts of pheromone were compared among populations by ANOVAs. SPSS 13.0 software was used for the calculations. The relative amounts of the 20 pheromone components were calculated (peak area/total peak area). Because the relative amounts constitute compositional data, they were transformed to logcontrasts prior to analysis [58]. 


\section{Chemical dimorphism}

A histogram with the Aitchison-transformed proportion of heptacosene revealed a clearly bimodal distribution without any overlap and, thus, allowed us to unambiguously assign males to the two different morphs (value < 0.55: $\mathrm{C}_{25}$-type; value $\geq 0.55: \mathrm{C}_{25} / \mathrm{C}_{27}$-type; see [40] for a detailed description of the dimorphism, figures showing chromatograms of both morphs and a histogram with the frequency distribution of the proportion of heptacosene in a population of 45 males). Chance variations in the proportion of $\mathrm{C}_{25^{-}}$and $\mathrm{C}_{25} / \mathrm{C}_{27}$-type males among families and among populations can greatly influence the outcome of statistical analyses on the chemical differentiation. Therefore, all of the analyses were performed on $\mathrm{C}_{25^{-}}$and $\mathrm{C}_{25} / \mathrm{C}_{27}$-type individuals combined as well as on $\mathrm{C}_{25}$-type individuals only. Thus, by excluding the $\mathrm{C}_{25} / \mathrm{C}_{27}$-type males from the analysis, we could make sure that statistical differences between populations or families are due to the overall chemical profile rather than just the frequency of the two distinct chemical morphs. The sample size of $\mathrm{C}_{25} / \mathrm{C}_{27}$-type males was too small for a reasonable analysis excluding the $\mathrm{C}_{25}$-type individuals.

\section{Population differentiation}

The number of describing variables was reduced by principal components analyses (PCA, Aitchison-transformed relative amounts of pheromone components as variables, varimax rotation, factor extraction: eigenvalues $>0.8$ ). The extracted PCA factors were used for DAs to test whether males of different populations can be separated based on their pheromone profiles. The number of PCA factors used for the DAs was restricted to a maximum of N/6 $(\mathrm{N}$ $=$ total number of males in the analysis) to avoid an excess of variables that may increase the risk of false-positive results. This procedure is conservative with regard to the hypotheses tested. A PCA and a DA was conducted for each of the two data sets, respectively. For PCA and DA, data set 1 was restricted to the local scale, including only subpopulations in close spatial vicinity (Würzburg, Biocenter, Würzburg, City, Veitshöchheim, Retzbach: maximum distance: $18 \mathrm{~km}$ ) to exclude regional effects on the outcome of the DA.

\section{Family differentiation}

To determine whether families within populations can be separated on the basis of the chemical profile, PCA and DA were conducted as described above for each population for which at least three families with five or more brothers were available. SPSS 13.0 software was used for the principal components and discriminant analyses.

\section{Relative effects of family and population affiliation on pheromone composition}

We conducted a multivariate nested ANOVA on the Aitchison-transformed relative peak areas with family membership as a nested factor within populations to assess the relative effects of family and population affiliation on the pheromone composition. For each data set, two ANOVAs were computed, one including both $\mathrm{C}_{25}$ and $\mathrm{C}_{25} / \mathrm{C}_{27}$-type males and the other one with $\mathrm{C}_{25}$-type individuals only. For every pheromone peak, the proportion of variance explained by the two factors was estimated by partial $\eta^{2}$-values [59-61]. To assess the relative effects of family and population on the pheromone composition, the $\eta^{2}$-values for both effects were compared over all peaks in paired t-tests after checking for normal distributions using Kolmogorov-Smirnov tests. All tests were computed using SPSS 13.0 software.

\section{Association between geographical and chemical distance}

The geographical distances between all sampled populations were calculated from the population coordinates with the DIVA-GIS software [62] and subsequently logtransformed. The chemical distances between the populations were calculated as follows: The mean for each of the 20 Aitchison-transformed pheromone components was calculated for all populations. The chemical distance between two given populations $\mathrm{x}$ and $\mathrm{y}$ was calculated as the Euclidean distance according to the formula $D_{\text {chem }}(x, y)=\sqrt{\sum_{i=1}^{n}\left(x_{i}-y_{i}\right)^{2}}$ with $\mathrm{x}_{\mathrm{i}}$ as the mean of pheromone component $\mathrm{i}$ of population $\mathrm{x}$. To be able to combine data sets 1 and 2, which differed slightly due to the differences in GC-MS set-ups, chemical distances were normalized. To this end, we assumed that the chemical distances between two populations that were sampled in both data sets were identical and served as a reference. Consequently, we were able to normalize the chemical distances of the two data sets with the distance between Würzburg and Schweinfurt, Würzburg and Düsseldorf, and Schweinfurt and Düsseldorf, respectively. The respective chemical distance was set to 1 in both data sets and all other values were converted to relative chemical distances. The normalizations based on the three different reference distances revealed qualitatively the same results in the following analyses, indicating that the procedure yielded valid results. The relationship between geographical and chemical distances was visualized using a scatter-plot and a linear regression line. We tested for a correlation between the matrices of geographical and chemical distances using a Mantel test that can deal with missing values using the software R 2.3.0 (mantel.test from the ncf package) $[63,64]$. P-values were calculated based on 100,000 resamplings. Mantel tests were performed with each dataset separately, and with the normalized com- 
bined dataset. All tests were conducted with both $\mathrm{C}_{25}$ - and $\mathrm{C}_{25} / \mathrm{C}_{27}$-type males and with $\mathrm{C}_{25}$-type-males only to exclude effects of different relative frequencies of both chemo-types across populations.

\section{Competing interests}

The author(s) declares that there are no competing interests.

\section{Authors' contributions}

All authors participated in the design of the study. MK and JK collected the specimens in Würzburg, Schweinfurt and Italy, they designed the GC-MS experiments, performed the statistical analysis and drafted the manuscript. ES conceived of the study, participated in the statistical analysis and interpretation of the data and critically revised the manuscript. All authors read and approved the final manuscript.

\section{Acknowledgements}

We thank Jeremy Field and Thomas Eltz for providing specimens from the UK and Düsseldorf. Paolo Rosa is acknowledged for his help in finding beewolves in Italy. Collection of specimens in Italy was made possible by a travel grant from the Arthur von Gwinner-foundation to JK. We thank Thomas Hovestadt for valuable suggestions concerning the statistical analysis and Johannes Penner for assistance with the calculations of the geographical distances in DIVA-GIS. This study was supported by a grant of the German Science Foundation (STR 532/I-2) and by a PhD fellowship of the German National Academic Foundation to MK.

\section{References}

I. Nelson DA, Soha JA: Perception of geographical variation in song by male Puget Sound white-crowned sparrows, Zonotrichia leucophrys pugetensis. Anim Behav 2004, 68:395-405.

2. Packert M, Martens J: Song dialects on the Atlantic islands: goldcrests of the Azores (Regulus regulus azoricus, R.r. sanctae-mariae, R.r. inermis). J Ornithol 2004, I 45(I):23-30.

3. Westcott DA, Kroon FJ: Geographic song variation and its consequences in the Golden Bowerbird. Condor 2002, I 04(4):750-760.

4. Gemeno C, Lutfallah AF, Haynes KF: Pheromone blend variation and cross-attraction among populations of the black cutworm moth (Lepidoptera: Noctuidae). Ann Entomol Soc Am 2000, 93(6): I322-1328.

5. Grosman DM, Salom SM, Ravlin FW, Young RW: Geographic and gender differences in semiochemicals in emerging adult southern pine beetle (Coleoptera: Scolytidae). Ann Entomol Soc Am 1997, 90(4):438-446.

6. Huang YP, Takanashi T, Hoshizaki S, Tatsuki S, Honda H, Yoshiyasu $Y$, Ishikawa $Y$ : Geographic variation in sex pheromone of Asian corn borer, Ostrinia furnacalis, in Japan. Journal of Chemical Ecology 1998, 24( ( 2):2079-2088.

7. McElfresh JS, Millar JG: Geographic variation in the pheromone system of the saturniid moth Hemileuca eglanterina. Ecology 200I, 82(I 2):3505-35I8.

8. Yatsynin VG, Rubanova EV, Okhrimenko NV: Identification of female-produced sex pheromones and their geographical differences in pheromone gland extract composition from click beetles (Coleoptera, Elateridae). Journal of Applied Entomology 1996, I 20(8):463-466.

9. Hamilton JGC, Maingon RDC, Alexander B, Ward RD, Brazil RP: Analysis of the sex pheromone extract of individual male Lutzomyia longipalpis sandflies from six regions in Brazil. Medical and Veterinary Entomology 2005, I 9(4):480-488.
10. Watts PC, Hamilton JGC, Ward RD, Noyes HA, Souza NA, Kemp SJ, Feliciangeli MD, Brazil R, Maingon RDC: Male sex pheromones and the phylogeographic structure of the Lutzomyia longipalpis species complex (Diptera : Psychodidae) from Brazil and Venezuela. Medical and Veterinary Entomology 2005, 73(4):734-743.

II. Ryan MA, Moore CJ, Walter GH: Individual variation in pheromone composition in Nezara viridula (Heteroptera: Pentatomidae): How valid is the basis for designating "pheromone strains"? Comparative Biochemistry and Physiology 1995, I I I: I89-193.

12. Aldrich JR, Lusby WR, Marron BE, Nicolaou KC, Hoffmann MP, Wilson LT: Pheromone Blends of Green Stink Bugs and Possible Parasitoid Selection. Naturwissenschaften 1989, 76:I73-I75.

13. Trivers RL: Parental investment and sexual selection. In Sexual selection and the descent of man, 187/-197/ Edited by: Campbell B. Chicago, Aldine; 1972:136-179.

14. Phelan PL: Evolution of sex pheromones and the role of asymmetric tracking. In Insect chemical ecology: an evolutionary approach Edited by: Roitberg BD, Isman MB. New York, Chapman and Hall; 1992.

15. Phelan PL: Evolution of mate-signaling in moths: phylogenetic considerations and predictions from the asymmetric tracking hypothesis. In The evolution of mating systems in insects and arachnids Edited by: Choe JC, Crespi BJ. Cambridge , Cambridge University Press; 1997.

16. Droney DC, Hock MB: Male sexual signals and female choice in Drosophila grimshawi (Diptera: Drosophilidae). J Insect Behav 1998, I I (I):59-7I.

17. Jones TM, Hamilton JGC: A role for pheromones in mate choice in a lekking sandfly. Anim Behav 1998, 56:891-898.

18. O'Loghlen AL, Rothstein SI: Female preference for the songs of older males and the maintenance of dialects in brownheaded cowbirds (Molothrus ater). Behav Ecol Sociobiol 2003, 53(2): 102-109.

19. Slater PJB: Fifty years of bird song research: a case study in animal behaviour. Anim Behav 2003, 65:633-639.

20. Halliday TR: The study of mate choice. In Mate choice Edited by: Bateson P. Cambridge , Cambridge University Press; 1983:3-32.

21. Vahed K: The function of nuptial feeding in insects: review of empirical studies. Biological Reviews 1998, 73(I):43-78.

22. Clayton DH: The influence of parasites on host sexual selection. Parasitology Today 1991, 7(12):329-334.

23. Hamilton WD, Zuk M: Heritable true fitness and bright birds a role for parasites. Science 1982, 2 I 8(4570):384-387.

24. Penn D, Potts WK: Chemical signals and parasite-mediated sexual selection. Trends In Ecology \& Evolution 1998, I3(10):391-396.

25. Andersson M: Sexual selection. Princeton, NJ, Princeton University Press; 1994.

26. Møller AP, Alatalo RV: Good-genes effects in sexual selection. Proc R Soc Lond B 1999, 266:85-91.

27. Wilkinson GS, Presgraves DC, Crymes L: Male eye span in stalkeyed flies indicates genetic quality by meiotic drive suppression. Nature 1998, 391:276-279.

28. Colegrave N, Kotiaho JS, Tomkins JL: Mate choice or polyandry: reconciling genetic compatibility and good genes sexual selection. Evolutionary Ecology Research 2002, 4(6):9l I-917.

29. Tregenza T, Wedell N: Genetic compatibility, mate choice and patterns of parentage. Mol Ecol 2000, 9(8): I0I3-1027.

30. Partridge L: Non-random mating and offspring fitness. In Mate choice Edited by: Bateson P. Cambridge , Cambridge University Press; 1983:227-255

31. Bateson P: Optimal outbreeding. In Mate choice Edited by: Bateson P. Cambridge , Cambridge University Press; 1983:257-277.

32. Pusey $A$, Wolf $M$ : Inbreeding avoidance in animals. Trends in Ecology \& Evolution 1996, I I(5):201-206.

33. Alexander RD: Natural selection and the analysis of human sociality. In Changing Scenes in Natural Sciences Edited by: Goulden CE. Academy of Sciences: Philadelphia; 1977:283-337.

34. Bischof $\mathrm{N}$ : The biological foundations of the incest taboo. Social Sciences Information 1972, I I:7-36.

35. Simon-Thomas RT, Poorter EPR: Notes on the behavior of males of Philanthus triangulum (Hymenoptera, Sphecidae). Tijdschrift voor Entomologie 1972, I I5(2): |4|-I5I. 
36. Strohm E: Allokation elterlicher Investitionen beim Europäischen Bienenwolf Philanthus triangulum Fabricius (Hymenoptera: Sphecidae). Berlin , Verlag Dr. Köster; 1995.

37. Evans HE, O'Neill KM: The natural history of North American beewolves. Ithaca, NY, Cornell University Press; 1988.

38. Schmitt T, Strohm E, Herzner G, Bicchi C, Krammer G, Heckel F, Schreier P: (S)-2,3-dihydrofarnesoic acid, a new component in cephalic glands of male european beewolves Philanthus triangulum. I Chem Ecol 2003, 29( I I):2469-2479.

39. Strohm E, Lechner K: Male size does not affect territorial behaviour and life history traits in a sphecid wasp. Animal Behaviour 2000, 59:183-191.

40. Kroiss J, Schmitt T, Schreier P, Strohm E, Herzner G: A selfish function of a "social" gland? A postpharyngeal gland functions as sex pheromone reservoir in males of a solitary wasp. Journal of Chemical Ecology 2006, 32:2763-2776.

4I. Herzner G, Schmitt T, Heckel F, Schreier P, Strohm E: Brothers smell similar: Variation in the sex pheromone of male European Beewolves Philanthus triangulum F. (Hymenoptera: Crabronidae) and its implications for inbreeding avoidance. Biological Journal of the Linnean Society 2006, 89:433-442.

42. Kaltenpoth M, Strohm E: The scent of senescence: Age-dependent changes in the composition of the marking pheromone of the male European beewolf, Philanthus triangulum. Journal of Insect Science 2006, 6:20.

43. Angioy AM, Desogus A, Barbarossa IT, Anderson P, Hansson BS: Extreme sensitivity in an olfactory system. Chemical Senses 2003, 28:279-284.

44. Kaissling KE: Insect olfaction. In Olfaction Edited by: Beidler LM New York, Springer Verlag; 1971:351-431.

45. Evans HE: Digger wasps as colonizers of new habitats (Hymenoptera: Aculeata). Journal of the New York Entomological Society 1974, 82:259-267.

46. Aspi ]: Inbreeding and outbreeding depression in male courtship song characters in Drosophila montana. Heredity 2000, 84(3):273-282.

47. Edmands S: Heterosis and outbreeding depression in inter population crosses spanning a wide range of divergence. Evolution 1999, 53(6): I757-1768.

48. Peer K, Taborskyi M: Outbreeding depression, but no inbreeding depression in haplodiploid ambrosia beetles with regular sibling mating. Evolution 2005, 59(2):317-323.

49. Fletcher DJC, Michener CD: Kin recognition in animals. Chichester, Jon Wiley \& Sons; 1987.

50. Hepper PG: Kin recognition - functions and mechanisms review. Biol Rev Cambridge Philosophic Soc 1986, 6 I (I):63-93.

51. Wright S: Isolation by distance. Genetics 1943, 28: | |4-138.

52. Futuyma DJ: Evolutionary biology. 3rd edition. Sunderland, MA Sinauer Associates; 1998.

53. Shields WM: The natural and unnatural history of inbreeding and outbreeding. In The natural history of inbreeding and outbreeding Edited by: Thornhill NW. Chicago , The University of Chicago Press; 1993.

54. Bateson P: Sexual imprinting and optimal outbreeding. Nature 1978, 273(5664):659-660.

55. Bateson P: Optimal outbreeding and the development of sex ual preferences in Japanese quail. Journal of Comparative Ethology 1980, 53(3):231-244.

56. Palmer CA, Edmands S: Mate choice in the face of both inbreed ing and outbreeding depression in the intertidal copepod Tigriopus californicus. Mar Biol 2000, I 36(4):693-698.

57. Herzner G, Goettler W, Kroiss J, Purea A, Webb A, Jakob PM, Roessler W, Strohm E: Males of a solitary wasp possess a postpharyngeal gland. Arthropod Structure \& Development 2007, 36:123-133.

58. Aitchison J: The statistical analysis of compositional data. London , Chapman \& Hall; 1986.

59. Cohen J: Eta-squared and partial eta-squared in fixed factor ANOVA designs. Educational and Psychological Measurement 1973 33:107-II2.

60. Keppel G: Design and analysis: A researcher's handbook. Englewood Cliffs, NJ , Prentice Hall; 1991.

6I. Olejnik S, Algina J: Generalized eta and omega squared statistics: Measures of effect size for some common research designs. Psychol Methods 2003, 8(4):434-447.

62. Mapping and analysis of spatial data [http://www.diva-gis.org]
63. Legendre P, Legendre L: Numerical ecology. Amsterdam, Elsevier Science B.V.; 1998.

64. Mantel N: The detection of disease clustering and a generalized regression approach. Cancer Research 1967, 27:209-220.
Publish with Bio Med Central and every scientist can read your work free of charge

"BioMed Central will be the most significant development for disseminating the results of biomedical research in our lifetime. "

Sir Paul Nurse, Cancer Research UK

Your research papers will be:

- available free of charge to the entire biomedical community

- peer reviewed and published immediately upon acceptance

- cited in PubMed and archived on PubMed Central

- yours - you keep the copyright 